\title{
Using Scientific Computing to Advance Wildland Fire Monitoring and Prediction
}

\author{
Janice Coen \\ National Center for Atmospheric Research \\ Mesoscale and Microscale Meteorology Laboratory \\ janicec@ucar.edu
}

\begin{abstract}
New technologies have transformed our understanding of wildland fire behavior, providing a better ability to observe them from a variety of platforms, simulate their growth with computational models, and interpret their frequency and controls in a global context. These tools have shown how wildland fires are among the extremes of weather events and can produce behaviors such as fire whirls, blow-ups, bursts of flame along the surface, and winds ten times stronger than ambient conditions, all of which result from the interactions between a fire and its atmospheric environment.

I will highlight current research in integrated weather - wildland fire computational modeling, fire detection, and observation, and their application to understanding and prediction. Coupled weather-wildland fire models tie numerical weather prediction models to wildland fire behavior modules to simulate the impact of a fire on the atmosphere and the subsequent feedback of these fire-induced winds on fire behavior, i.e. how a fire "creates its own weather”. NCAR's CAWFE ${ }^{\circledR}$ modeling system has been used to explain fundamental fire phenomena and reproduce the unfolding of past fire events. Recent work, in which CAWFE has been integrated with satellite-based active fire detection data, addresses the challenges of applying it as an operational forecast tool. This newer generation of tools brought many goals within sight - rapid fire detection, nearly ubiquitous monitoring, and recognition that many of the distinctive characteristics of fire events are reproducible and perhaps predictable in real time. Concurrently, these more complex tools raise new challenges. I conclude with innovative model-data fusion approaches to overcome some of these remaining puzzles.
\end{abstract}

\section{Author Keywords}

Natural hazards; fire remote sensing; computational fluid dynamics

\section{BIOGRAPHY}

Dr. Janice Coen is a Project Scientist at the National Center for Atmospheric Research in Boulder, Colorado. She received a B.S. in Engineering Physics from Grove City College and an M.S. and Ph.D. from the Department of Geophysical Sciences at the University of Chicago. She investigates wildland fire behavior and its interaction with weather using computational fluid dynamics models and by analyzing infrared imagery of wildland fires. She has developed two coupled numerical weather prediction - wildland fire behavior models that have become widespread in the research community and transformed how people interpret fire behavior. Her current work applies these

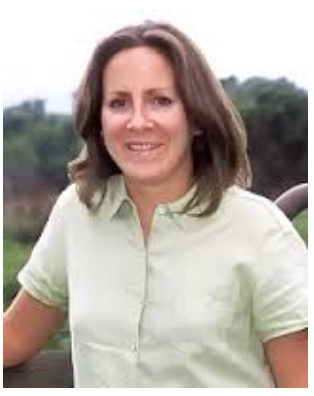
models with airborne and satellite fire and fuel remote sensing data to decipher the unfolding of large wildland fire events, improve firefighter safety, understand the impact of fuel accumulation and drought on wildfires, and serve as nextgeneration model/data assimilation systems to forecast wildfire growth.

She served as Associate Editor for the International Journal of Wildland Fire, on the Editorial Board of Environmental Modelling \& Software, and on the Board of Directors of the International Association of Wildland Fire.

http://www2.mmm.ucar.edu/people/coen/

\footnotetext{
Permission to make digital or hard copies of part or all of this work for personal or classroom use is granted without fee provided that copies are not made or distributed for profit or commercial advantage and that copies bear this notice and the full citation on the first page. Copyrights for third-party components of this work must be honored. For all other uses, contact the Owner/Author(s). Copyright is held by the owner/author(s)

HPDC'17, June 26-30, 2017, Washington, DC, USA.

ACM ISBN 978-1-4503-4699-3/17/06.

DOI: http://dx.doi.org/10.1145/3078597.3091519
} 